
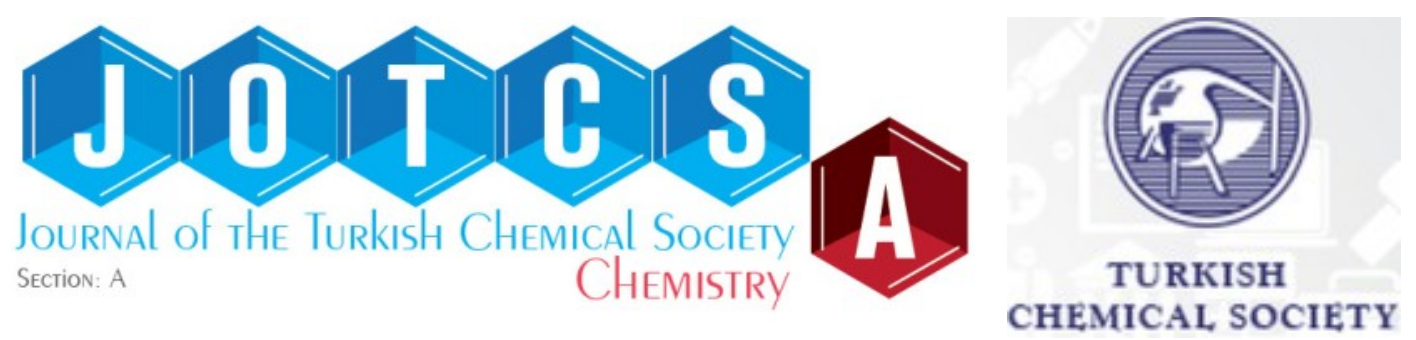

\title{
Utilization of Kiwi Peel Lignocellulose as Fillers in Poly(Lactic Acid) Films
}

\author{
Ece Sogut ${ }^{1 *}$ D, Atıf Can Seydim ${ }^{1}$
}

${ }^{1}$ Suleyman Demirel University, Food Engineering Department, Isparta, 32260, Turkey

\begin{abstract}
Lignocellulosic structures extracted from agricultural wastes have great potential in re-designing sustainable packaging materials. In this study, the utilization of kiwifruit peels (KFP) (unt) and lignocellulosic structures extracted from KFP, which were alkali-treated (al), acid-treated (ac), and acetylated (ace), in poly(lactic acid) (PLA) films were investigated. Untreated and treated lignocellulosic structures were added to PLA film-forming solutions at $5 \%$ (w/w based on PLA). The film samples were characterized by their mechanical, water vapor permeability (WVP), FTIR, and optical properties. FTIR results presented that the acid treatment and acetylation have changed the chemical structure of KPF, which resulted in changes in intensities and peak shifts between $1400-1900 \mathrm{~cm}^{-1}$. WVP of the films containing KPF-based lignocellulosic structures was lower than control PLA films $(p<0.05)$. The addition of KPF-based lignocellulosic structures increased the tensile strength and elastic modulus $(p>0.05)$ compared to PLA control films. Films including acid-treated lignocellulosic structures had high opacity and relatively low lightness values $(p<0.05)$. These results showed that adding lignocellulosic structures into PLA films is a promising method to improve the film properties.
\end{abstract}

Keywords: Kiwifruit peels, Lignocellulose, Modification, Poly(lactic acid)

Submitted: November 16, 2021. Accepted: February 03, 2022.

Cite this: Sogut E, Seydim AC. Utilization of Kiwi Peel Lignocellulose as Fillers in Poly(Lactic Acid) Films. JOTCSA. 2022;9(1):283-94.

DOI: https://doi.org/10.18596/jotcsa.1024326.

*Corresponding author. E-mail: ececagdas@sdu.edu.tr.

\section{INTRODUCTION}

The rise in energy demand, the increase in carbon gas emissions, and the depletion of fossil-based sources have recently raised environmental concerns $(1,2)$. The circular economy promotes the transition from petroleum-based materials to renewable materials and greener processes for obtaining energy and materials. Biowastes are an abundant and inexpensive source. Their complete utilization to extract added-value materials is an appealing option from an eco-friendly standpoint (2-5). Among the various biomasses, lignocellulosic biomass accounts for nearly $70 \%$ of total plant biomass (4). Thus, the environmental problems and depletion of fossil resources have increased interest in green and sustainable chemistry, which focuses on lignocellulose-based materials as a promising, abundant, and renewable resource for different materials (6-8). The main constituents found in lignocellulosic structures are cellulose (homopolymer), hemicelluloses (heteropolymer), and lignin (aromatic polymers) (7-9). To convert them into various bio-based compounds, individual fractions could be recovered from lignocellulosic biomass (10).

Researchers have used pre-treatments to separate these main structures (lignin, hemicellulose) from lignocellulosic structures, modify, improve their reactivity by extracting those valuable constituents, and change degrees of crystallization and polymerization (11-15). Alkaline or acid hydrolysis has been widely used as a chemical pretreatment technique $(16,17)$. Among the various pretreatments, alkaline de-lignification destroys the lignin structure and breaks linkages between lignin and carbohydrate to make the latter more 
accessible (18). Hydrothermal treatments are highcapacity treatments for hemicellulose solubilization while also producing cellulose and lignin-rich structures that are open to being treated to extract these components $(19,20)$. Besides, acetylation has been used to plasticize the cellulosic fibers, substituting hydroxyl groups with acetyl groups to make the material more hydrophobic, stabilize the material against water, and enhance the degradation and stability (21). Ozone treatment is another biomass pretreatment method in which it oxidizes the structure to remove lignin and hemicellulose (22).

The use of lignocellulosic structures as fillers for biobased polymers has gained popularity due to their better mechanical strength, wide range of availability, and being suitable for various chemical structure-based modifications (23-28). Many studies have examined the incorporation of agrowastes into natural biopolymers such as starch, protein, cellulose, poly(lactic) acid (PLA), and polyhydroxy butyrate (PHB) to create bio-based plastics $(23,26,29-31)$. Among biopolymers, PLA has been vastly studied due to its easily processed structure, having similar characteristics to conventional plastics, intrinsic biodegradability and biocompatibility, compostability, thermoplastic nature, and outstanding mechanical performance (32). However, to widen the application of PLAbased materials, PLA has been studied to modify its structure by various alternative methods such as blending with other polymers, reactive extrusion, using crosslinking agents or chain extender, chemical or physical modifications, and use of reinforcing agents including inorganic fillers and natural fibers (33-36). Among these applications, the addition of lignocellulosic structures such as corncob (37), yerba mate $(32,38)$, bamboo, switchgrass (39), nanofibers from lignocellulose biomass (40) into PLA has also been gained attention by researchers.

Fruit peels, such as kiwifruit peels, are from the agro-food industry with promising potential as an appropriate raw material for use in a biorefinery (7). Kiwifruit processing creates wastes with bio-active properties of various sectors such as cosmetic, food, and pharmaceutical industries due to their bioactive molecules having health-promoting properties (4144). After extracting active compounds (kaempferol and quercetin derivatives) from kiwifruit peel, the obtained solid fraction is primarily composed of lignocellulosic structures (45). Incorporating lignocellulosic structures obtained from agro-wastes like kiwifruit peel as reinforcements typically lowers cost and water uptake while increasing mechanical strength (46). Arrieta et al. (38) studied the effect of lignocellulosic-based mate nanoparticles extracted from yerba mate residue on the properties of PLA films. They reported enhanced thermal stability, increased flexibility, processability, UV light blocking effect, and an appropriate disintegration in compost. However, interfacial adhesion between PLA and natural fibers extracted from agro-wastes is one of the most important issues (37). Generally, weak interaction between PLA and lignocellulosic structures has been reported in the literature (4749). Thus, research on the addition of modified lignocellulosic structures to improve the adhesion in thermoplastics/lignocellulose composites are gaining interest.

The food industry has been commercializing the kiwi fruit in diverse processed forms, even though the kiwi fruit is commonly consumed as fresh (50). Therefore, the byproducts such as the peel of kiwi fruit have been increasing and are still underexplored (51). However, a great interest in these byproducts has increased due to their high concentration of bioactive molecules (52). The characterization of kiwi fruit byproducts has been studied by many researchers (51); however, the valorization of these byproducts as fillers in biopolymers is required more studies to confirm their utilization. Besides, it has been reported that the direct use of these fillers might result in incompatibility problems, which chemical modifications on lignocellulosic structures could recover. PLA reinforcement with various chemically modified lignocellulosic fibers has been rarely studied. Thus, this study aimed to examine the valorization of kiwifruit peels in PLA films as fillers followed by different pre-treatments including alkali, acetylation, and acid treatments, and further evaluate regarding mechanical, water vapor permeability (WVP), Fourier transform infrared spectroscopy (FTIR), and optical properties, whether to determine the potential of kiwifruits byproduct in the food packaging applications.

\section{MATERIALS AND METHODS}

\section{Materials}

Kiwi fruits (KF) were provided from a local producer in Isparta (Turkey) and peeled to collect kiwi fruit peels (KFP). KFPs were then dried at $60{ }^{\circ} \mathrm{C}$ for $24 \mathrm{~h}$ and ground with a high-speed blender. After screening the obtained particles with suitable meshes, particles smaller than $300 \mu \mathrm{m}$ in size were used in the experiments. Homogenized KFPs were coded as "unt" and stored at $4^{\circ} \mathrm{C}$ until use. Poly(lactic acid) (PLA) (4032D; molecular weight of $80,000-100,000 \mathrm{~g} / \mathrm{mol}, 1.25 \mathrm{~g} / \mathrm{cm}^{3}$ of specific gravity, melt flow index of $5.89 \mathrm{~g} / 10 \mathrm{~min}$ ) was from NatureWorks LLC (Minnetonka, MN, USA) and other chemicals including sulfuric acid $\left(\mathrm{H}_{2} \mathrm{SO}_{4}\right)$, ethanol, sodium hydroxide $(\mathrm{NaOH})$, chloroform, glacial acetic acid, and magnesium nitrate $\left(\mathrm{Mg}\left(\mathrm{NO}_{3}\right)_{2}\right)$ were purchased from Sigma-Aldrich (St. Louis, Missouri, USA).

Extraction of Cellulose-Rich Structures from Kiwi Peels and Characterization 
The extraction steps of cellulose-rich structures from KFPs are shown in Figure 1.



Figure 1: Schematic representation of extraction steps.

KFPs were de-lignified in an alkaline medium using $\mathrm{NaOH}$ at $5 \%(\mathrm{w} / \mathrm{w})$ with a liquid: solid ratio of $10 \%$ $(\mathrm{w} / \mathrm{w})$ at $121^{\circ} \mathrm{C}$ for 15 min. Black liquor was separated by filtration followed by washing to neutral $\mathrm{pH}$. The filtrate was dried and coded as alkali-treated (al). The alkali-treated solid part was then modified by acid treatment (ac) and acetylation (ace) (53). Acid-treated samples were obtained after subjecting the alkali-treated solid part to $\mathrm{H}_{2} \mathrm{SO}_{4}(5 \%, \mathrm{w} / \mathrm{w})$ at a liquid: solid ratio of $5 \%(\mathrm{w} / \mathrm{w})$ at $50^{\circ} \mathrm{C}$ for $3 \mathrm{~h}$. After mild hydrolysis, the filtrate was washed several times and dried for $24 \mathrm{~h}$ at $80^{\circ} \mathrm{C}$. The acetylation reaction was performed by soaking the alkali-treated solid part in glacial acetic acid. The reaction was carried out by adding ethanol and concentrated $\mathrm{H}_{2} \mathrm{SO}_{4}$ (acid catalyst) at $50{ }^{\circ} \mathrm{C}$ for 
3 h. After washing with water several times, the filtrate was obtained and dried for $24 \mathrm{~h}$ at $80^{\circ} \mathrm{C}$. The al-, ac-, and ace-treated KFP-based fillers were

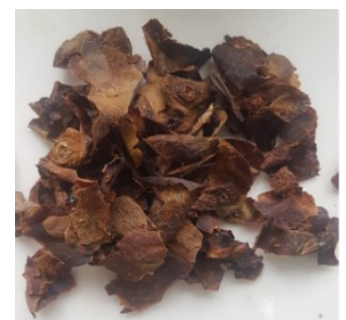

Dried kiwi peels

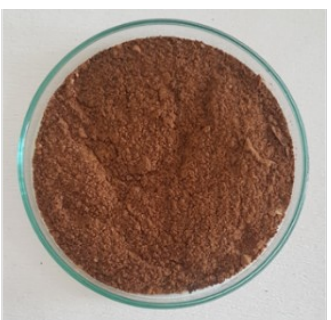

Dried and grinded kiwi peels untreated

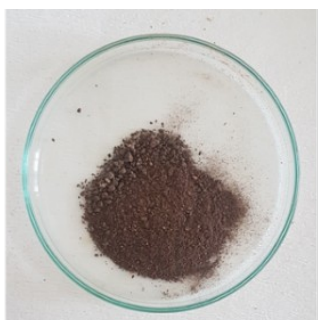

Alkali treated

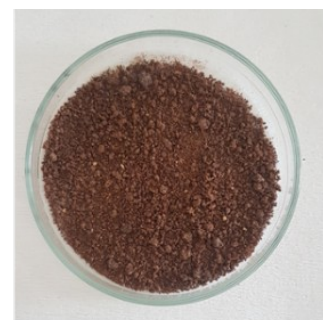

Acid treated

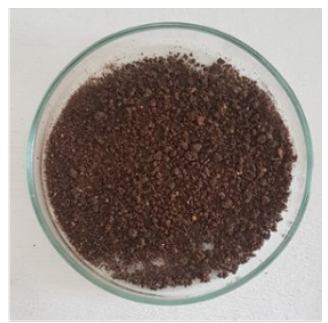

Acetylated

Figure 2: Pictures of extracted structures.

Lignin and cellulose contents of dried KFPs (unt) and extracted cellulose-rich structures were determined according to Sogut and Cakmak's methods (54). The Fourier transform infrared (FTIR) spectra, ranging from $500 \mathrm{~cm}^{-1}$ to $4000 \mathrm{~cm}^{-1}$, for KFPs (unt) and extracted cellulose-rich structures were obtained by Spectrum Two FTIR spectrometer (Perkin Elmer, USA) with an attenuated total reflectance (ATR) module.

\section{Preparation of PLA films}

PLA at $6 \%(\mathrm{w} / \mathrm{w})$ was dissolved in chloroform and poured on Teflon-coated Petri dishes. Reinforced film samples were obtained by mixing KFP-based fillers at $5 \%(\mathrm{w} / \mathrm{w})$ with PLA film-forming solution. Homogeneous film-forming solutions were cast and dried at room temperature. The pouring amount of film-forming solution was adjusted to control the film thickness. All film samples were conditioned at $25{ }^{\circ} \mathrm{C}$ and $53 \%$ relative humidity $(\mathrm{RH})$ for one week before characterization analyses. PLA film, which did not include any filler, was named control film. Other film samples were called PLA-unt, PLA-al, PLA-ac, and PLA-ace for PLA films, including unt, al, ac, and ace, respectively (Figure 3 ). The thickness of six randomly selected points was measured by a digital micrometer (Quantu-Mike IP65, Mitutoyo, Japan, $\pm 0.001 \mathrm{~mm})$.
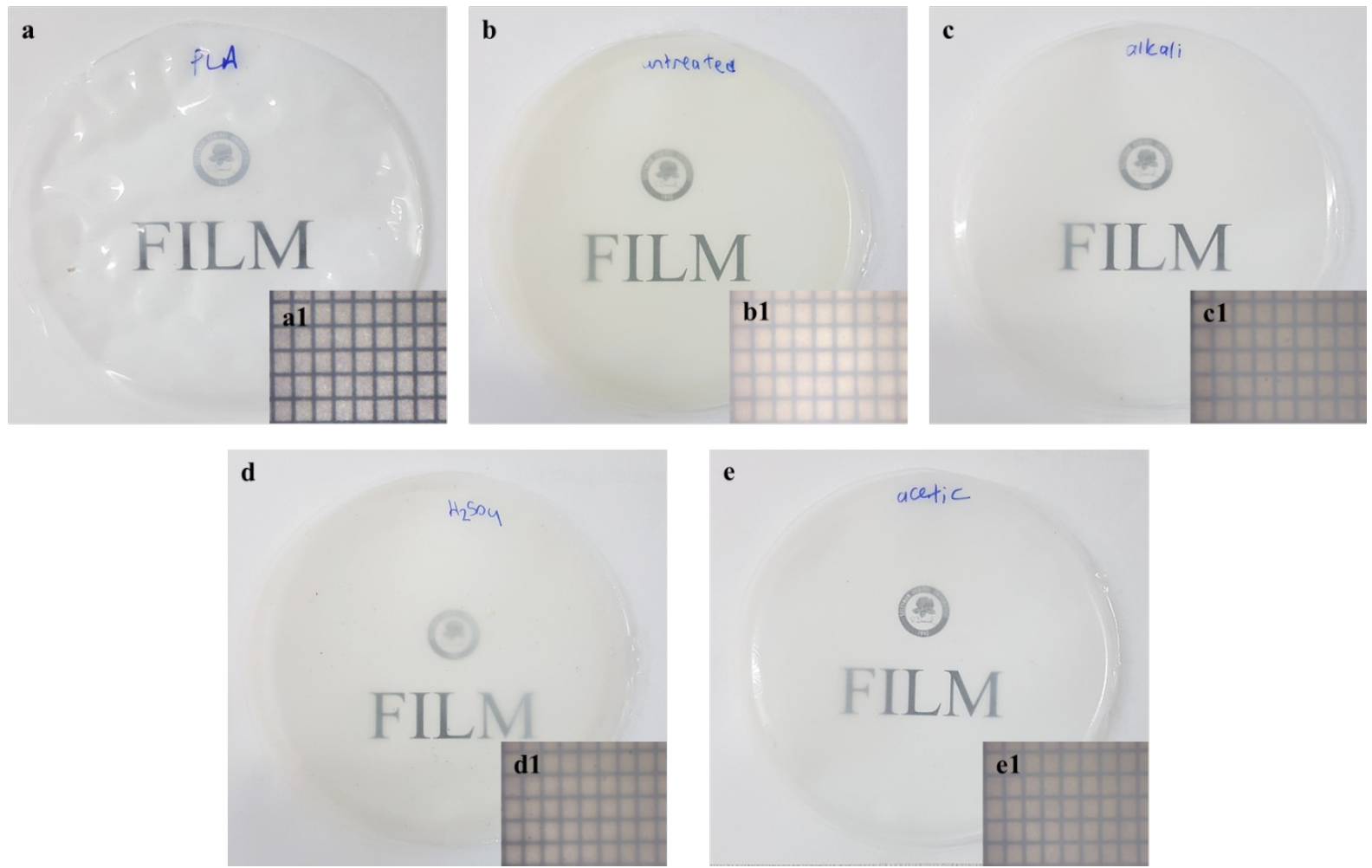

Figure 3: Pictures of film samples $(a=P L A, b=P L A-u n t, c=P L A-a l, d=P L A-a c, e=P L A-a c e$ and number 1 denotes images taken under a stereomicroscope (Carl Zeiss Stemi 5800, Oberkochen Germany) processed with Zeiss Zen (blue edition) software and with the scale of $0.1 \mathrm{~mm}$ ) 


\section{Characterization of the Film Samples}

Fourier transform infrared (FTIR) spectroscopy FTIR spectra of film samples were recorded using Spectrum Two FTIR spectrometer (Perkin Elmer, USA) equipped with a horizontal ATR module, which was recorded from $500 \mathrm{~cm}^{-1}$ to $4000 \mathrm{~cm}^{-1}$ at $25^{\circ} \mathrm{C}$ (with a resolution of $4 \mathrm{~cm}^{-1}$ ).

Mechanical properties and water vapor permeability (WVP) of film samples

The mechanical properties, tensile strength (TS), and elongation-at-break values $(E)$ were determined by the ASTM standard method D882 (55). Films were mounted in the film-extension grips of the universal testing machine (Lloyd LR5, AMETEK, Inc, UK) and stretched at $50 \mathrm{~mm} \cdot \mathrm{min}^{-1}$.

The WVP of films was determined according to the E96/E96M-16 gravimetric method (56). Film samples were exposed to $100 \% \mathrm{RH}$, and the permeability measurements were performed by weighing the cups periodically (every $1.5 \mathrm{~h}$ for $48 \mathrm{~h}$ ) at $25^{\circ} \mathrm{C}$.

Optical properties of film samples

The opacity of film samples was determined using the absorption spectrum of the film sample $(1 \times 4 \mathrm{~cm}$ rectangular film strips) between $400 \mathrm{~nm}$ and 800 $\mathrm{nm}$ by a UV-visible spectrophotometer (Shimadzu,
UV-1601, Japan). The opacity was expressed as absorbance units per film thickness (AU nm. $\mathrm{min}^{-1}$ ). The transmittance values were obtained at $450 \mathrm{~nm}$ as percent transmittance with a UV-visible spectrophotometer (Shimadzu, UV-1601, Japan).

The color of the prepared films was determined by a Minolta Chroma Meter (CR-400, Konica Minolta, Inc., Japan). CIE L* (lightness), a* (red-green) and b* (yellow-blue) coordinates in the color space were recorded by using a white standard calibration plate $(Y=92.7, x=0.3160, y=0.3321)$ as the background for color measurement of the films.

\section{Statistical Analysis}

An analysis of variance (ANOVA) and Tukey's multiple comparison tests were used to find the differences between film samples at a $95 \%$ confidence level. The statistical analysis was performed using Minitab 17 software (Minitab Inc., Brandon, UK). Three observations were performed for each sample, and each experiment was replicated three times.

\section{RESULTS AND DISCUSSION}

\section{Properties of kiwi fruit peels}

The cellulose and lignin contents of untreated and treated kiwi peels are shown in Table 1.

Table 1: Lignin and cellulose contents of extracted structures.

\begin{tabular}{lcc}
\hline Sample & Cellulose (\%) & Lignin (\%) \\
\hline Untreated & $13.66 \pm 2.22^{\mathrm{c}}$ & $29.93 \pm 7.74^{\mathrm{a}}$ \\
\hline Alkali treated & $37.03 \pm 2.66^{\mathrm{b}}$ & $19.28 \pm 1.46^{\mathrm{a}}$ \\
\hline Acid treated & $65.28 \pm 4.49^{\mathrm{a}}$ & $16.35 \pm 1.77^{\mathrm{a}}$ \\
\hline Acetylated & $35.93 \pm 6.27^{\mathrm{b}}$ & $19.90 \pm 5.38^{\mathrm{a}}$ \\
\hline superscripts in the same column are significantly different $(\mathrm{p}<0.05)$.
\end{tabular}

It was observed that untreated KFP consisted of $13.66 \pm 2.22$ and $29.93 \pm 7.74 \%$ cellulose and lignin, respectively. After the alkali treatment, cellulose content increased while lignin content decreased, showing the partial removal of lignin constituents. The same trend was also observed in acid treatment and acetylation, which might be due to the functionalization of lignocellulosic structures by reacting with cellulosic $-\mathrm{OH}$ groups. The acetylation process might also modify the fiber structure, causing an increase in plasticization and a reduction in the water affinity of cellulose (57). Similarly, Narender and Priya Dasan (58) and Kocaman and Ahmetli (53) observed a reduction in lignin concentration after acid treatment and acetylation of coir pith and hazelnut shells, respectively.

The FTIR spectra of KFP and treated KFPs are shown in Figure 4. 


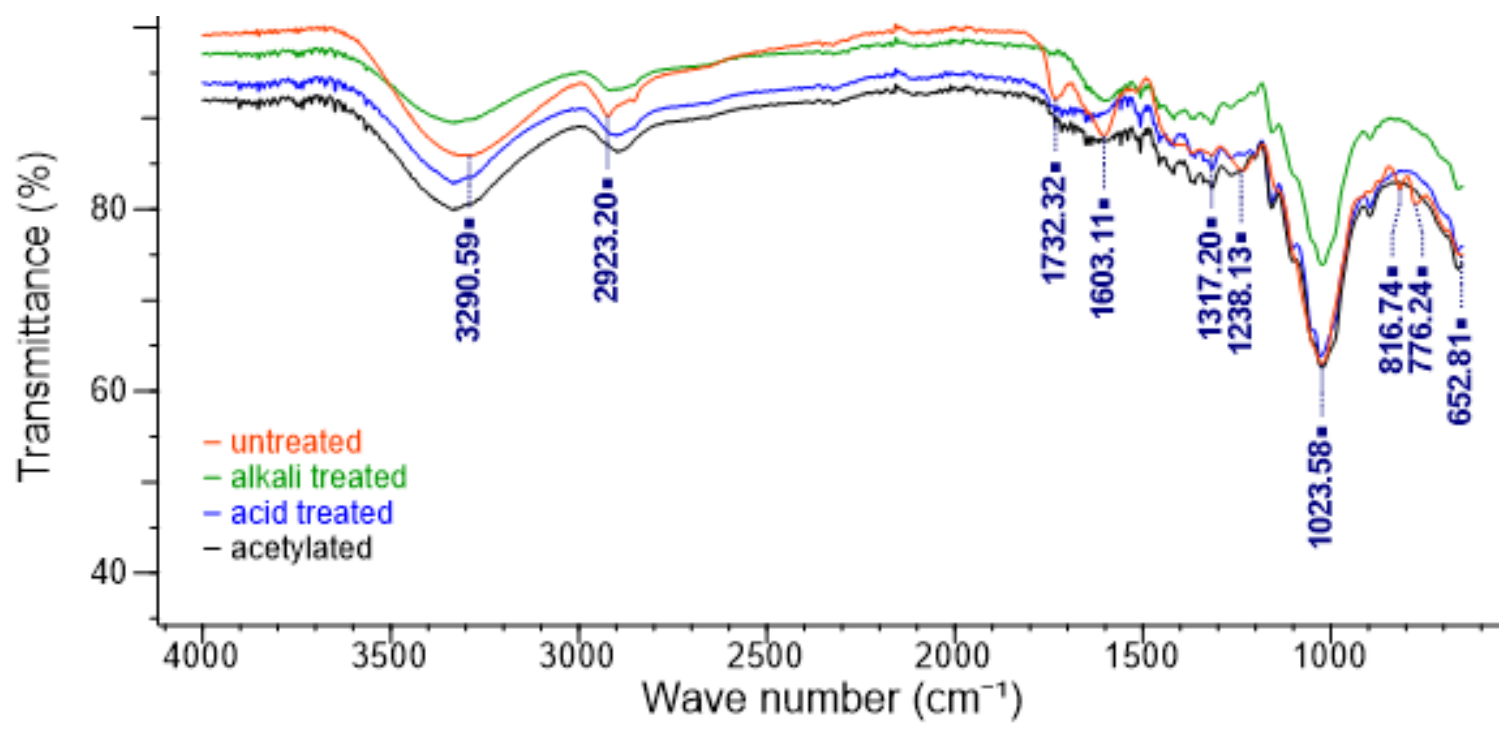

Figure 4: FTIR spectra of untreated, alkali-treated, acid-treated, and acetylated kiwi peels.

The peaks found at $3300 \mathrm{~cm}^{-1}, 1600 \mathrm{~cm}^{-1}$, and $1700 \mathrm{~cm}^{-1}$ belong to the $\mathrm{O}-\mathrm{H}$ stretching, the aromatic $\mathrm{C}=\mathrm{C}$ stretching, and the unconjugated $\mathrm{C}=\mathrm{O}$ groups stretching. The peaks found at 1220 $\mathrm{cm}^{-1}$ are also assigned to the $\mathrm{C}-\mathrm{O}$ stretching in lignin rings. The peak at $900-1100 \mathrm{~cm}^{-1}$ belongs to the cellulosic linkages, and the changes in the intensity of these peaks are associated with the changes in cellulose levels after the treatments. The disappearance of peaks around $1700-1800 \mathrm{~cm}^{-1}$ observed after the chemical treatments can be related to the decline in or the removal of hemicellulose-based structures. Besides, the intensity of peaks at $1220 \mathrm{~cm}^{-1}$ was lower than the untreated KFP structures, which can be correlated with the reduction in lignin concentration due to the chemical treatments. The band at $1245 \mathrm{~cm}^{-1}$ might be observed due to the presence of the acetate groups. Similar behavior was observed by Sreekala et al. (59) for oil palm fiber and Kocaman (60) for apricot kernel shells after various chemical modifications.

\section{Properties of film samples}

The thickness, water vapor permeability (WVP), and mechanical properties of film samples are shown in Table 2.

Table 2: Thickness, water vapor permeability (WVP), and mechanical properties (TS, E) of film samples.

\begin{tabular}{|c|c|c|c|c|}
\hline Sample & $\begin{array}{c}\text { Thickness } \\
(\mu \mathrm{m})\end{array}$ & $\begin{array}{c}\text { WVP } \\
\left(\mathrm{g} \cdot \mathrm{mm} \cdot \mathrm{kPa}^{-1} \cdot \mathrm{h}^{-1} \cdot \mathrm{m}^{-2}\right)\end{array}$ & TS (MPa) & E (\%) \\
\hline PLA & $113 \pm 15^{a}$ & $0.15 \pm 0.05^{a}$ & $19.55 \pm 1.88^{a}$ & $4.32 \pm 0.19^{a}$ \\
\hline PLA-unt & $150 \pm 20^{a}$ & $0.12 \pm 0.01^{b}$ & $21.44 \pm 1.66^{\mathrm{a}}$ & $3.98 \pm 0.53^{a}$ \\
\hline PLA-al & $128 \pm 35^{a}$ & $0.11 \pm 0.03^{b}$ & $27.55 \pm 7.81^{a}$ & $4.79 \pm 0.61^{a}$ \\
\hline PLA-ac & $150 \pm 21^{a}$ & $0.11 \pm 0.02^{b}$ & $29.67 \pm 5.25^{a}$ & $4.92 \pm 0.62^{a}$ \\
\hline PLA-ace & $128 \pm 38^{a}$ & $0.10 \pm 0.01^{b}$ & $26.14 \pm 4.38^{a}$ & $4.70 \pm 0.25^{a}$ \\
\hline
\end{tabular}

The thickness of film samples slightly increased with the addition of fillers; however, the fillers did not significantly affect the thickness of film samples. The highest thickness values were observed in PLAunt and PLA-ac film samples due to less compatibility and lower interaction between the $\mathrm{CH}$ film matrix and the filler.

The addition of KPF-based fillers into PLA films significantly lowered the WVP of film samples, and the lowest values were found in PLA-ace film sample $(p<0.05)$. The dispersion of fiber particles within the film matrix might affect the diffusion way of water molecules by changing the polarity of polymer and the path length of water molecules (61). Similar results were observed by Khalil et al. (62), who studied the effect of bamboo fibers on the thermomechanical properties of carrageenan films, and Valdés García et al. (63) used almond skin residues to improve the properties of PCL films.

The application of different chemical treatments had various effects on the mechanical properties of film samples. Compared to neat PLA films, TS and E values increased after alkali treatment and modifications made by acetylation and acid treatment. The PLA films, including untreated KFP, also showed an increase in TS while a reduction was observed in elongation. The differences between untreated fiber added PLA film and PLA films, 
including alkali-treated and modified KFP, might be due to increased cellulose content and improved adhesive characteristics obtained after chemical treatments (64). Acid-treated kiwi peels had the highest cellulose concentration, followed by alkalitreated and acetylated samples, while untreated peels had the lowest cellulose concentration. The presence of high cellulose fiber content might favor the interfacial adhesion between PLA and filler, resulting in better interactions with higher tensile strength. The addition of untreated peels had lower TS values, showing the modification improved the filler-matrix adhesion at the interface through the reaction with end groups of PLA (65). The direct use of lignocellulosic structures in polymeric matrices results in poor compatibility, requiring modifications to obtain a larger surface area for better interactions between filler and polymer (66). The chemical modifications used in the experiments might substitute the hydroxyl groups of peels with other functional groups depending on the used method, making the fiber more hydrophobic and thus enhancing the TS of polymer (21).

Similarly, Kocaman et al. (64) also reported enhanced mechanical properties for biobased composite materials when chemically modified coconut waste particles were incorporated. The elongation at break is related to the flexibility of polymer chains; thus, an inverse effect is expected between TS and elongation. However, in this study, both TS and $E$ values increased with fillers. The presence of lignin could also contribute to the plasticization of PLA due to the lignin-PLA bonding at the interphase regions (26).

The optical properties of film samples are shown in Table 3.

Table 3: Optical properties of film samples.

\begin{tabular}{cccccc}
\hline Sample & $\boldsymbol{L}^{*}$ & $\mathbf{a}^{*}$ & $\boldsymbol{b}^{*}$ & $\begin{array}{c}\text { Transmittance } \\
\mathbf{( \% )}\end{array}$ & $\begin{array}{c}\text { Opacity } \\
\mathbf{( A U} \mathbf{~ n m} / \boldsymbol{\mu m})\end{array}$ \\
\hline PLA & $96.33 \pm 0.27^{\mathrm{a}}$ & $0.14 \pm 0.03^{\mathrm{a}}$ & $1.82 \pm 0.11^{\mathrm{c}}$ & $47.85 \pm 6.70^{\mathrm{a}}$ & $4.42 \pm 0.32^{\mathrm{a}}$ \\
\hline PLA-unt & $91.72 \pm 1.30^{\mathrm{b}}$ & $0.63 \pm 1.23^{\mathrm{a}}$ & $11.19 \pm 2.15^{\mathrm{a}}$ & $27.58 \pm 2.01^{\mathrm{ab}}$ & $4.99 \pm 0.30^{\mathrm{a}}$ \\
\hline PLA-al & $91.42 \pm 1.93^{\mathrm{b}}$ & $1.28 \pm 0.60^{\mathrm{a}}$ & $6.11 \pm 1.37^{\mathrm{b}}$ & $27.80 \pm 7.33^{\mathrm{ab}}$ & $4.23 \pm 0.18^{\mathrm{a}}$ \\
\hline PLA-ac & $92.05 \pm 1.80^{\mathrm{b}}$ & $1.40 \pm 0.76^{\mathrm{a}}$ & $7.86 \pm 1.74^{\mathrm{b}}$ & $24.40 \pm 4.34^{\mathrm{b}}$ & $4.26 \pm 0.41^{\mathrm{a}}$ \\
\hline PLA-ace & $93.49 \pm 0.49^{\mathrm{ab}}$ & $0.66 \pm 0.29^{\mathrm{a}}$ & $4.80 \pm 0.60^{\mathrm{bc}}$ & $29.10 \pm 1.67^{\mathrm{ab}}$ & $4.97 \pm 0.89^{\mathrm{a}}$ \\
\hline \multicolumn{6}{c}{ a-c Different superscripts in the same column are significantly different $(\mathrm{p}<0.05)}$.
\end{tabular}

PLA control film had the high $L^{*}$ value indicating its brightness and transparency, while its $a *$ and $b *$ values were close to zero. The lightness of films, including untreated and alkali-treated KFPs was the lowest, followed by acid-treated and acetylated KFP added PLA films $(\mathrm{p}<0.05)$. The $a^{*}$ and $b^{*}$ values significantly increased with the addition of fillers as indicative of a red, yellowish/brown coloration, which is due to the typical color of KFPs. This behavior was also reflected as a significant decrease in transmittance and a significant increase in opacity. The lowest value was measured for the PLA-ac film, which might be due to the weak dispersion of the acid-treated lignin within the PLA matrix. The low transmittance values demonstrated the potential applicability of these films as UVblocking films mainly for light-sensitive products (67). Similar behavior was observed by Wang et al. (68) for PLA and grafted PLA films, including lignin.

The FTIR spectra of film samples are shown in Figure 5. 


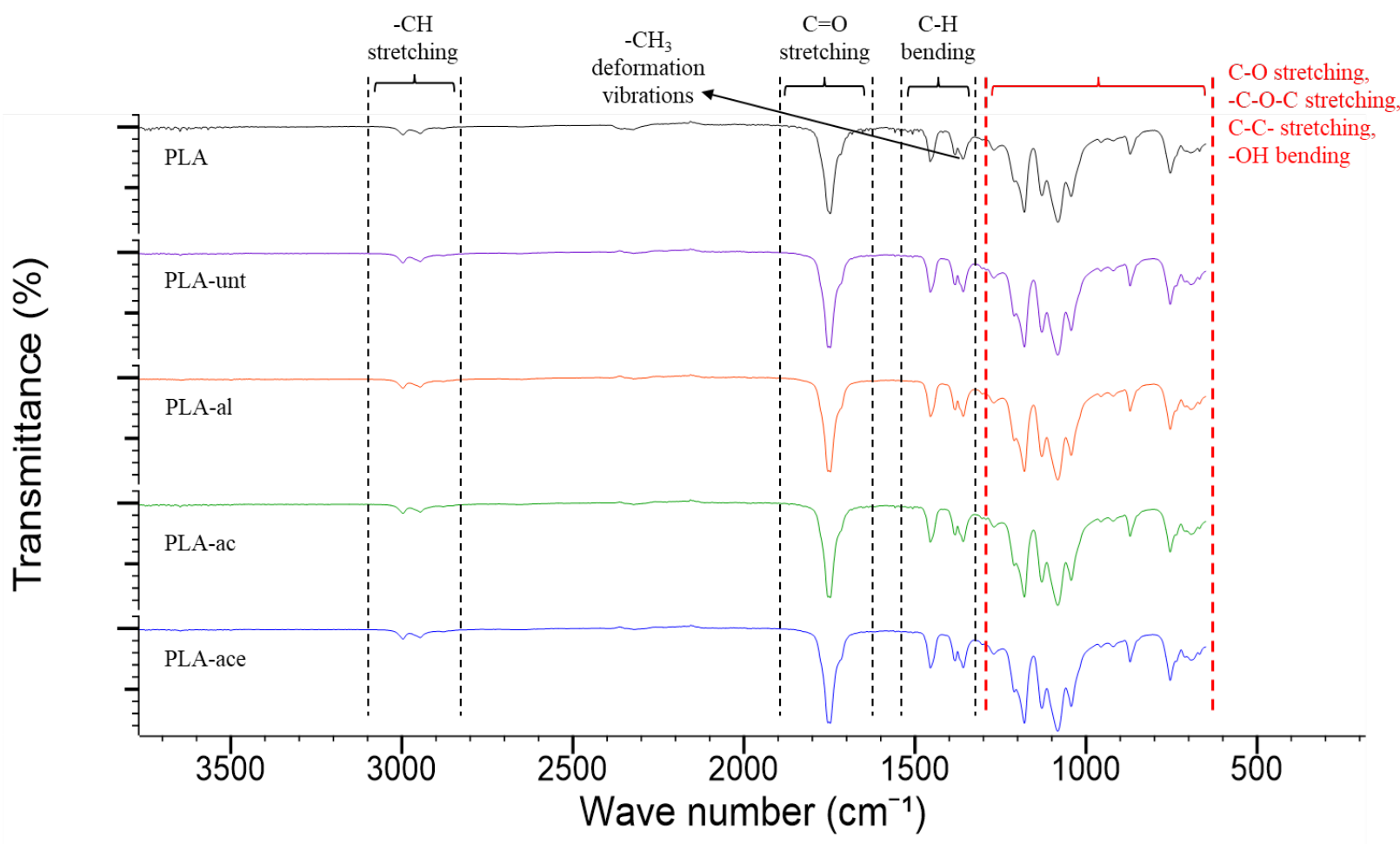

Figure 5: FTIR spectra of film samples.

The major peaks of PLA showed in Figure 5 are at $1750 \mathrm{~cm}^{-1}$ assigned to the $-\mathrm{C}=\mathrm{O}$ stretching vibration of the ester group, and the peaks between 1300$1400 \mathrm{~cm}^{-1}$ corresponded to the asymmetric and symmetric $-\mathrm{CH}_{3}$ deformation vibrations, respectively. The other peaks identified between 800 and $1300 \mathrm{~cm}^{-1}$ are related to the $-\mathrm{C}-\mathrm{O}-\mathrm{C}-$ stretching of the ester groups, the $\mathrm{C}-\mathrm{O}$ stretching, the $-\mathrm{OH}$ bending, and the $-\mathrm{C}-\mathrm{C}$ - stretching of the amorphous phase (69). Iglesias Montes et al. (70) observed similar FTIR spectrums for PLA bilayer films containing cellulose nanocrystals or lignin nanoparticles. The structure of PLA films did not vary with the addition of KFP-based fillers, as confirmed by any differences in FTIR spectra compared to those of neat PLA films. Opposite to these results, Nair et al. (26) found considerable interactions between the nanocellulose fibrils with high lignin content and PLA film matrix, which might be due to the differences in lignin particle size having an impact on particle-matrix interface adhesion.

\section{CONCLUSION}

Lignocellulosic structures were extracted from KFPs by alkali treatment and alkali combined chemical treatments such as acetylation and acid treatment. It was observed that the lignin concentration decreased while the cellulose concentration increased after alkali treatment and chemical modifications of lignocellulosic structures extracted from KFPs. The obtained structures were then added to the PLA film-forming solutions to enhance the
PLA film properties as a food packaging material. The WVP, TS, and elongation of PLA films were enhanced with alkali-treated and alkali combined chemically modified structures. However, no significant changes in the chemical structure of PLA upon the addition of various KFP-based fibers as confirmed by FTIR spectra. In conclusion, alkali treatment and different modifications were found to have the potential to modify the lignocellulosic structures extracted from agricultural wastes to be used as fillers in the polymeric matrix for the improvement of film properties.

\section{CONFLICT OF INTEREST}

The authors declare that there is no conflict of interest.

\section{ACKNOWLEDGMENTS}

This study was conducted at Suleyman Demirel University Food Engineering Department Laboratories. Special thanks to Oguz Sogut for lignin characterization.

\section{REFERENCES}

1. Dragone G, Kerssemakers AAJ, Driessen JLSP, Yamakawa CK, Brumano LP, Mussatto SI. Innovation and strategic orientations for the development of advanced biorefineries. Bioresource Technology. 2020 Apr;302:122847. <DOI .

2. Ubando AT, Felix CB, Chen $\mathrm{W}-\mathrm{H}$. Biorefineries in circular bioeconomy: A comprehensive review. Bioresource 
Technology. 2020 Mar;299:122585. <DOI .

3. Gullón B, Gullón P, Eibes G, Cara C, De Torres A, LópezLinares JC, et al. Valorisation of olive agro-industrial byproducts as a source of bioactive compounds. Science of The Total Environment. 2018 Dec;645:533-42. <DOI>.

4. de Hoyos-Martínez PL, Erdocia X, Charrier-El Bouhtoury $F$, Prado R, Labidi J. Multistage treatment of almonds waste biomass: Characterization and assessment of the potential applications of raw material and products. Waste Management. 2018 Oct;80:40-50. <DOI $>$.

5. Terzioğlu P, Güney F, Parın FN, Şen İ, Tuna S. Biowaste orange peel incorporated chitosan/polyvinyl alcohol composite films for food packaging applications. Food Packaging and Shelf Life. $2021 \mathrm{Dec} ; 30: 100742$. <DOI>.

6. Liu $\mathrm{C}$, Hu J, Zhang $\mathrm{H}$, Xiao R. Thermal conversion of lignin to phenols: Relevance between chemical structure and pyrolysis behaviors. Fuel. 2016 Oct;182:864-70. $\leq \mathrm{DOI}>$.

7. Morales A, Gullón B, Dávila I, Eibes G, Labidi J, Gullón $P$. Optimization of alkaline pretreatment for the coproduction of biopolymer lignin and bioethanol from chestnut shells following a biorefinery approach. Industrial Crops and Products. 2018 Nov;124:582-92. <DOI >.

8. Terzioğlu P, Parın FN, Sıcak Y. Lignin Composites for Biomedical Applications: Status, Challenges and Perspectives. In: Sharma S, Kumar A, editors. Lignin [Internet]. Cham: Springer International Publishing; 2020 [cited 2022 Feb 5]. p. 253-73. (Springer Series on Polymer and Composite Materials). ISBN: 978-3-03040663-9. $\leq U R L>$.

9. Laurichesse $S$, Avérous L. Chemical modification of lignins: Towards biobased polymers. Progress in Polymer Science. 2014 Jul;39(7):1266-90. <DOI>.

10. Dávila I, Gullón B, Labidi J, Gullón P. Multiproduct biorefinery from vine shoots: Bio-ethanol and lignin production. Renewable Energy. 2019 Nov;142:612-23. $\leq \mathrm{DOI}>$.

11. Kumar P, Barrett DM, Delwiche MJ, Stroeve P. Methods for Pretreatment of Lignocellulosic Biomass for Efficient Hydrolysis and Biofuel Production. Ind Eng Chem Res. 2009 Apr 15;48(8):3713-29. <DOI>.

12. Kothari R, Singh DP, Tyagi VV, Tyagi SK. Fermentative hydrogen production-An alternative clean energy source. Renewable and Sustainable Energy Reviews. 2012 May; $16(4): 2337-46$. $\leq$ DOI $>$.

13. Guo F, Fang Z, Xu CC, Smith RL. Solid acid mediated hydrolysis of biomass for producing biofuels. Progress in Energy and Combustion Science. 2012 Oct;38(5):672-90. <DOI $>$.

14. Quéméneur $M$, Hamelin J, Barakat $A$, Steyer J-P, Carrère $H$, Trably $E$. Inhibition of fermentative hydrogen production by lignocellulose-derived compounds in mixed cultures. International Journal of Hydrogen Energy. 2012 Feb;37(4):3150-9. <DOI $>$.

15. Wulf C, Kaltschmitt M. Life cycle assessment of biohydrogen production as a transportation fuel in Germany. Bioresource Technology. 2013 Dec;150:466-75. $\leq \mathrm{DOI}>$.

16. Cheng Y-S, Zheng Y, Yu CW, Dooley TM, Jenkins BM, VanderGheynst JS. Evaluation of High Solids Alkaline Pretreatment of Rice Straw. Appl Biochem Biotechnol. 2010 Nov;162(6):1768-84. <DOI>.

17. Zhang J, Ma X, Yu J, Zhang X, Tan T. The effects of four different pretreatments on enzymatic hydrolysis of sweet sorghum bagasse. Bioresource Technology. 2011 Mar;102(6):4585-9. <DOI $>$.

18. Kim JS, Lee YY, Kim TH. A review on alkaline pretreatment technology for bioconversion of lignocellulosic biomass. Bioresource Technology. 2016 Jan;199:42-8. <DOI $>$.

19. Dávila I, Gordobil O, Labidi J, Gullón P. Assessment of suitability of vine shoots for hemicellulosic oligosaccharides production through aqueous processing. Bioresource Technology. 2016 Jul;211:636-44. <DOI $>$.

20. Morales A, Labidi J, Gullón P. Hydrothermal treatments of walnut shells: A potential pretreatment for subsequent product obtaining. Science of The Total Environment. 2021 Apr;764:142800. <DOI>.

21. Silva NGS, Maia TF, Mulinari DR. Effect of Acetylation with Perchloric Acid as Catalyst in Sugarcane Bagasse Waste. Journal of Natural Fibers. 2021 Feb 9;1-15. $\leq \mathrm{DOI}>$.

22. Sun $Y$, Cheng J. Hydrolysis of lignocellulosic materials for ethanol production: a review. Bioresource Technology. 2002 May;83(1):1-11. <DOI>.

23. Thakur VK, Thakur MK, Raghavan P, Kessler MR. Progress in Green Polymer Composites from Lignin for Multifunctional Applications: A Review. ACS Sustainable Chem Eng. 2014 May 5;2(5):1072-92. <DOI>.

24. Spiridon I, Leluk K, Resmerita AM, Darie RN. Evaluation of PLA-lignin bioplastics properties before and after accelerated weathering. Composites Part B: Engineering. 2015 Feb;69:342-9. <DOI $>$.

25. Klapiszewski $\measuredangle$, Bula $K$, Sobczak M, Jesionowski $T$. Influence of Processing Conditions on the Thermal Stability and Mechanical Properties of PP/Silica-Lignin Composites. International Journal of Polymer Science. 2016;2016:1-9. $\leq \mathrm{DOI}>$.

26. Nair SS, Chen H, Peng Y, Huang Y, Yan N. Polylactic Acid Biocomposites Reinforced with Nanocellulose Fibrils with High Lignin Content for Improved Mechanical, Thermal, and Barrier Properties. ACS Sustainable Chem Eng. 2018 Aug 6;6(8):10058-68. <DOI $>$.

27. Yang W, Fortunati E, Dominici F, Giovanale G, Mazzaglia A, Balestra GM, et al. Effect of cellulose and lignin on disintegration, antimicrobial and antioxidant properties of PLA active films. International Journal of Biological Macromolecules. 2016 Aug;89:360-8. <DOI 2.

28. Terzioğlu P, Parın FN. Polyvinyl alcohol-corn starchlemon peel biocomposite films as potential food packaging. 
Celal Bayar University Journal of Science. 2020;16(4):373-8.

29. Holmgren A, Brunow G, Henriksson G, Zhang L, Ralph J. Non-enzymatic reduction of quinone methides during oxidative coupling of monolignols: implications for the origin of benzyl structures in lignins. Org Biomol Chem. 2006;4(18):3456. <DOI>.

30. Graupner N. Application of lignin as natural adhesion promoter in cotton fibre-reinforced poly(lactic acid) (PLA) composites. J Mater Sci. 2008 Aug;43(15):5222-9. $\leq \mathrm{DOI}>$.

31. Brodin M, Vallejos M, Opedal MT, Area MC, ChingaCarrasco G. Lignocellulosics as sustainable resources for production of bioplastics-A review. Journal of Cleaner Production. 2017 Sep;162:646-64. <DOI>.

32. Beltrán FR, Arrieta MP, Gaspar G, de la Orden MU, Martínez Urreaga J. Effect of Iignocellulosic Nanoparticles Extracted from Yerba Mate (Ilex paraguariensis) on the Structural, Thermal, Optical and Barrier Properties of Mechanically Recycled Poly(lactic acid). Polymers. 2020 Jul 29;12(8):1690. <DOI>.

33. Beltrán FR, Gaspar G, Dadras Chomachayi M, JalaliArani $A$, Lozano-Pérez $A A$, Cenis $J \mathrm{~L}$, et al. Influence of addition of organic fillers on the properties of mechanically recycled PLA. Environ Sci Pollut Res. 2021 May;28(19):24291-304. <DOI>.

34. Beltrán FR, Infante $C$, de la Orden $M U$, Martínez Urreaga J. Mechanical recycling of poly(lactic acid): Evaluation of a chain extender and a peroxide as additives for upgrading the recycled plastic. Journal of Cleaner Production. 2019 May;219:46-56. <DOI>.

35. Beltrán FR, de la Orden MU, Martínez Urreaga J. Amino-Modified Halloysite Nanotubes to Reduce Polymer Degradation and Improve the Performance of Mechanically Recycled Poly(lactic acid). J Polym Environ. 2018 Oct;26(10):4046-55. <DOI >.

36. Arrieta M, Samper M, Aldas M, López J. On the Use of PLA-PHB Blends for Sustainable Food Packaging Applications. Materials. 2017 Aug 29;10(9):1008. <DOI>.

37. Faludi G, Dora G, Renner K, Móczó J, Pukánszky B. Biocomposite from polylactic acid and lignocellulosic fibers: Structure-property correlations. Carbohydrate Polymers. 2013 Feb;92(2):1767-75. <DOI $>$.

38. Arrieta MP, Peponi L, López D, Fernández-García M. Recovery of yerba mate (Ilex paraguariensis) residue for the development of PLA-based bionanocomposite films. Industrial Crops and Products. 2018 Jan;111:317-28. $\leq$ DOI $>$.

39. Xie J, Hse C-Y, Shupe TF, Hu T. Physicochemical characterization of lignin recovered from microwaveassisted delignified lignocellulosic biomass for use in biobased materials. J Appl Polym Sci. 2015 Oct $20 ; 132(40): 1-7 . \leq$ DOI $>$.

40. Mohammadalinejhad S, Almasi H, Esmaiili M. Physical and release properties of poly(lactic acid)/nanosilverdecorated cellulose, chitosan and lignocellulose nanofiber composite films. Materials Chemistry and Physics. 2021 Aug;268:124719. <DOI $>$.

41. Latocha P. The Nutritional and Health Benefits of Kiwiberry (Actinidia arguta) - a Review. Plant Foods Hum Nutr. 2017 Dec;72(4):325-34. <DOI>.

42. Richardson DP, Ansell J, Drummond LN. The nutritional and health attributes of kiwifruit: a review. Eur J Nutr. 2018 Dec;57(8):2659-76. <DOI .

43. Chamorro $F$, Carpena $M$, Nuñez-Estevez B, Prieto MA, Simal-Gandara J. Valorization of Kiwi by-Products for the Recovery of Bioactive Compounds: Circular Economy Model. Proceedings. 2020 Nov 9;70(1):9. <DOI>.

44. Pinto D, Delerue-Matos C, Rodrigues F. Bioactivity, phytochemical profile and pro-healthy properties of Actinidia arguta: A review. Food Research International. 2020 Oct; 136:109449. <DOI>.

45. Almeida D, Pinto D, Santos J, Vinha AF, Palmeira J, Ferreira $\mathrm{HN}$, et al. Hardy kiwifruit leaves (Actinidia arguta): An extraordinary source of value-added compounds for food industry. Food Chemistry. 2018 Sep;259:113-21. <DOI $>$.

46. Sun $Y$, Yang L, Lu X, He C. Biodegradable and renewable poly(lactide)-lignin composites: synthesis, interface and toughening mechanism. J Mater Chem A. 2015;3(7):3699-709. <DOI>.

47. Bax B, Müssig J. Impact and tensile properties of PLA/Cordenka and PLA/flax composites. Composites Science and Technology. 2008 Jun;68(7-8):1601-7. $\leq \mathrm{DOI}$.

48. Bledzki AK, Jaszkiewicz A, Scherzer D. Mechanical properties of PLA composites with man-made cellulose and abaca fibres. Composites Part A: Applied Science and Manufacturing. 2009 Apr;40(4):404-12. <DOI>.

49. Petinakis E, Yu L, Edward G, Dean K, Liu H, Scully AD. Effect of Matrix-Particle Interfacial Adhesion on the Mechanical Properties of Poly(lactic acid)/Wood-Flour Micro-Composites. J Polym Environ. 2009 Jun;17(2):8394. <DOI $>$.

50. Zhu C, Gong Q, Li J, Zhang Y, Yue J, Gao J. Research progresses of the comprehensive processing and utilization of kiwifruit. Storage and Process. 2013;13(1):57-62.

51. Dias M, Caleja C, Pereira C, Calhelha RC, Kostic M, Sokovic $M$, et al. Chemical composition and bioactive properties of byproducts from two different kiwi varieties. Food Research International. 2020 Jan; 127:108753. $\leq \mathrm{DOI}>$.

52. Wojdyło A, Nowicka P, Oszmiański J, Golis T. Phytochemical compounds and biological effects of Actinidia fruits. Journal of Functional Foods. 2017 Mar;30:194-202. <DOI >.

53. Kocaman S, Ahmetli G. Effects of Various Methods of Chemical Modification of Lignocellulose Hazelnut Shell Waste on a Newly Synthesized Bio-based Epoxy Composite. J Polym Environ. 2020 Apr;28(4):1190-203. $<$ DOI $>$. 
54. Sogut E, Cakmak H. Utilization of carrot (Daucus carota L.) fiber as a filler for chitosan based films. Food Hydrocolloids. 2020 Sep;106:105861. <DOI $>$.

55. Anonymous. Standard Test Method for Tensile Properties of Thin Plastic Sheeting [Internet]. ASTM International; 2002. $\leq$ URL $>$.

56. Anonymous. Standard test methods for water vapor transmission of materials: E96/E96M- 16. American Society for Testing and Materials Standard; 2016.

57. Nam TH, Ogihara S, Tung NH, Kobayashi S. Effect of alkali treatment on interfacial and mechanical properties of coir fiber reinforced poly(butylene succinate) biodegradable composites. Composites Part B: Engineering. 2011 Sep;42(6):1648-56. <DOI>.

58. Narendar R, Priya Dasan K. Chemical treatments of coir pith: Morphology, chemical composition, thermal and water retention behavior. Composites Part B: Engineering. 2014 Jan;56:770-9. <DOI $>$.

59. Sreekala M, Kumaran M, Joseph S, Jacob M, Thomas S. Oil palm fibre reinforced phenol formaldehyde composites: influence of fibre surface modifications on the mechanical performance. Applied Composite Materials. $2000 ; 7(5): 295-329$.

60. Kocaman S. Preparation and characterization of natural waste reinforced epoxy resin matrix composites modified with different chemicals. Uluslararası Muhendislik Arastirma ve Gelistirme Dergisi. 2019 Jan 31;11(1):77-86. $\leq \mathrm{DOI}>$.

61. Khalil H, Tye Y, Saurabh C, Leh C, Lai T, Chong E, et al. Biodegradable polymer films from seaweed polysaccharides: A review on cellulose as a reinforcement material. Express Polymer Letters. 2017;11(4):244-65.

62. Abdul Khalil HPS, Che Mohamad HCI, Khairunnisa AR, Owolabi FAT, Asniza M, Rizal S, et al. Development and characterization of bamboo fiber reinforced biopolymer films. Mater Res Express. 2018 Jul 24;5(8):085309. $<$ DOI $>$.

63. Valdés García A, Ramos Santonja M, Sanahuja $A B$, Selva $M$ del $C G$. Characterization and degradation characteristics of poly( $\varepsilon$-caprolactone)-based composites reinforced with almond skin residues. Polymer Degradation and Stability. 2014 Oct;108:269-79. <DOI>.

64. Kocaman S, Karaman M, Gursoy M, Ahmetli G. Chemical and plasma surface modification of lignocellulose coconut waste for the preparation of advanced biobased composite materials. Carbohydrate Polymers. 2017 Mar;159:48-57. <DOI $>$.

65. Wang $N$, Zhang $C$, Weng $Y$. Enhancing gas barrier performance of polylactic acid/lignin composite films through cooperative effect of compatibilization and nucleation. J Appl Polym Sci. 2021 Apr 15;138(15):50199. $<$ DOI $>$.

66. Kabir MM, Wang H, Lau KT, Cardona F. Chemical treatments on plant-based natural fibre reinforced polymer composites: An overview. Composites Part B: Engineering. 2012 Oct;43(7):2883-92. <DOI>.

67. Kim Y, Suhr J, Seo H-W, Sun H, Kim S, Park I-K, et al. All Biomass and UV Protective Composite Composed of Compatibilized Lignin and Poly (Lactic-acid). Sci Rep. 2017 Apr;7(1):43596. <DOI $>$.

68. Wang N, Zhang $C$, Weng $Y$. Enhancing gas barrier performance of polylactic acid/lignin composite films through cooperative effect of compatibilization and nucleation. J Appl Polym Sci. 2021 Apr 15;138(15):50199. $\leq \mathrm{DOI}>$.

69. Muller J, Casado Quesada A, González-Martínez C, Chiralt A. Antimicrobial properties and release of cinnamaldehyde in bilayer films based on polylactic acid (PLA) and starch. European Polymer Journal. 2017 Nov;96:316-25. <DOI $>$.

70. Iglesias Montes ML, Luzi F, Dominici F, Torre L, Cyras VP, Manfredi LB, et al. Design and Characterization of PLA Bilayer Films Containing Lignin and Cellulose Nanostructures in Combination With Umbelliferone as Active Ingredient. Front Chem. 2019 Mar 26;7:157. $\leq \mathrm{DOI}>$. 
